\title{
Human Biomonitoring in Occupational Health for Exposure Assessment
}

\author{
Kate Jones \\ Health and Safety Executive, Buxton, UK
}

My long-time colleague, Dr. John Cocker, used to proclaim human biomonitoring (HBM) a "useful tool" [1]. His reason to do so was to broaden its use as much as possible; only by being widely used and better understood could it really live up to its promise - to enable better exposure control and to evaluate interventions.

The primary purpose of HBM in occupational health is exposure assessment, although it can also have a role in health surveillance (e.g., CoSHH regulation 11 [2]). I hope here to demonstrate that HBM really is a useful tool that should be deployed more widely for exposure assessment.

Human biomonitoring (also called biological monitoring) is the measurement of the body burden of chemical compounds, elements, or their metabolites, in biological fluids (usually blood or urine, although many media have been used including breath, saliva, hair, nails, etc.). Its role in occupational health is primarily to assess the exposure of workers to the chemicals that they use $[3,4]$. In this regard, HBM is another exposure assessment tool alongside environmental monitoring techniques such as air monitoring and surface wipe sampling. The value of HBM over these other tools is that it measures systemic uptake (what has actually got into the body from all sources) rather than potential exposure. The differences between actual (systemic uptake) and potential exposure are influenced by a variety of factors including the physi-

\begin{tabular}{ll}
\hline Karger & ( 2020 British Crown copyright \\
karger@karger.com & This article is licensed under the Creative Commons Attribution- \\
www.karger.com/pjp & $\begin{array}{l}\text { NonCommercial-NoDerivatives } 4.0 \text { International License (CC BY- } \\
\text { NC-ND) (http://www.karger.com/Services/OpenAccessLicense). } \\
\text { Uage and distribution for commercial purposes as well as any dis- } \\
\text { tribution of modified material requires written permission. }\end{array}$ \\
Open decess &
\end{tabular}

cochemical properties of the substance, the routes of exposure, the use of personal protective equipment (such as respirators and gloves) and the way that tasks are undertaken.

To understand the role of HBM, it is useful to consider the exposure-disease paradigm (Fig. 1), a well-known model that shows how environmental toxicants might cause disease. It is a continuum that includes the emission of a contaminant from a source into the environment (air, surfaces, water, etc.) through human exposure and uptake to the occurrence of a health effect [5]. As the exposure and uptake continues, then early, reversible, effects begin to be seen in cells and tissues (measurement of these changes is referred to as biological effect monitoring); if exposure still continues, then eventually the early effects will progress to clinical effects and overt disease will result.

The role of occupational health professionals should, above all, be about ill-health prevention, although the aspects of diagnosis, rehabilitation and compensation are also important. And prevention is the guiding principle of HBM; through the identification of excessive exposures and the subsequent evaluation of any interventions, before any health effects are apparent. The efficient use of $\mathrm{HBM}$ as a tool in occupational exposure assessment therefore has a number of requirements, including being undertaken by those familiar with the work (the process- 
Fig. 1. Exposure to disease paradigm.

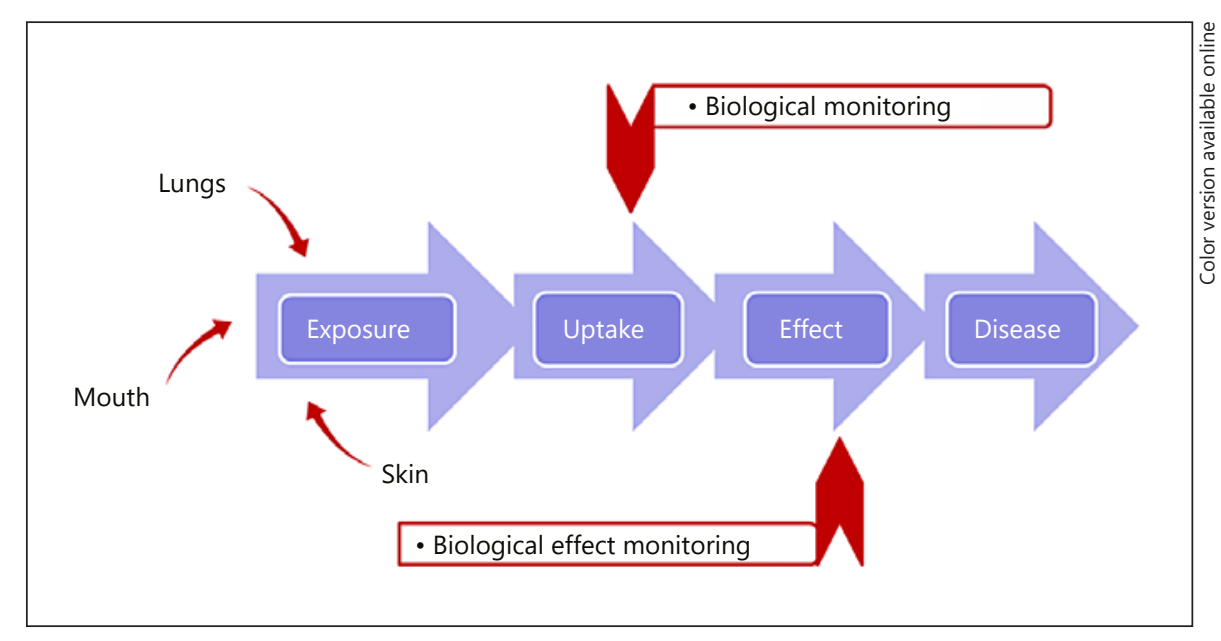

es, exposure control measures and worker behaviour) and closely associated with it (on site or regularly "walking the floor"). It is only by understanding the workplace and non-workplace sources of exposure that occupational health professionals can adequately interpret and act on HBM results appropriately.

The first step is recognise that HBM in the majority of cases measures the chemical hazard itself or a direct breakdown product (metabolite) and therefore gives no direct information on health effects and is essentially exposure assessment. In some limited cases, e.g. mercury, it is possible to directly link a level in a biological sample with a known health outcome [6]. For mercury, this is possible because the measurement of urinary mercury reflects several months' exposure, and there is a significant body of evidence to link graduated exposure levels to defined health effects. However, these are the exceptions. Generally, the knowledge allows a correlation of biomarker levels with airborne exposure levels (where inhalation-only comparison data are available) and this, in turn, enables an assessment of whether exposure is "acceptable" or not, based on compliance with an airborne limit. In these situations, it is clear that HBM data are no more "medical" than air monitoring results, other than they reflect "actual" exposures to workers rather than potential exposures. Interpretation in Great Britain for example states "Where a BMGV is exceeded, it does not necessarily mean ... that ill health will occur... this will give an indication that investigation into current control measures and work practices is necessary" [7]. Similar interpretive guidance is given for the ACGIH Biological Exposure Indices [3].

The appropriate handling of data remains a key point, but this is true whether the data is HBM or some other form of exposure assessment. In light of the recent General Data Protection Regulation (GDPR) ${ }^{1}$, suitable systems for managing and securing data are required at all levels within a company (and beyond) for any data that can be construed as "personal." HBM data are specific measurements relating to individuals, their specific roles and tasks within the process and their particular behaviours and work patterns, and so obviously the results have implications for individuals, but such implications could also apply to personal environmental monitoring results (breathing zone air monitoring or hand wipe samples, for instance).

Unlike air sampling, which is often mandated by law or has regulatory limits, HBM is usually voluntary (except for lead $(\mathrm{Pb})$, discussed later). Informed consent is also critical to running an HBM programme; workers need to understand and agree to what will be measured, how, why and what will be done with results (including who will see them). This means that efforts have to be made to inform workers about the programme and its aims, but this is often positive. If workers genuinely understand the purpose of the monitoring and see that it can provide information on whether their exposures are being adequately controlled and how their own behaviour can impact their exposure, then they will be more likely to engage with the programme and show interest in the results. Where results indicate that the control measures need to be improved then they have a case to expect such corrections from management but where results indicate that human behaviour is a factor, they can also be persuaded to improve their own use of PPE or ways of working directly

\footnotetext{
1 https://gdpr-info.eu/
} 
for their own benefit. Sharing of results, with appropriate consent, can also foster team working and create positive peer influence to improve PPE compliance and suggest improvements to working practice. There are few who appreciate better the mechanics of the work task and what is feasible than the actual workers themselves. When done well, without coercion or threat of punitive consequences, such schemes can not only improve exposure control in the workplace but also management-operator relations and workflow.

Some HBM is classified as health surveillance; definitions vary, but an example is "assessment of the state of health of an employee, as related to exposure to substances hazardous to health" [2]. This terminology may imply a clinical relevance but, for example, in Great Britain it is stipulated that "health surveillance" records should not contain confidential clinical data and conclusions should relate only to the employee's fitness to work (ACOP11 [2]). Not all health surveillance requires a medical practitioner; for example, skin checks are part of health surveillance for substances that can cause dermatitis but these can be performed by a "responsible person" (although an occupational health professional should oversee the scheme and be responsible for investigating any incidence of symptoms). In Great Britain, there is a subsidiary category of "medical surveillance," which applies to a very limited set of high hazard exposures including asbestos, lead [8], ionising radiation, compressed air and specific chemical hazards (including vinyl chloride monomer, certain chromates and benzene (Schedule 6 [2]). This medical surveillance must be performed by "appointed" doctors (with specific training) and may include clinical examination as well as noting exemptions from certain types of work or exposure for individuals. For lead, this includes mandatory blood lead measurements with specified levels that determine the doctor's subsequent actions (including removing the worker from further exposure) [8].

Across Europe, there is only one binding Biological Limit Value ${ }^{2}$, for blood lead measurements, set at $70 \mu \mathrm{g}$ $\mathrm{Pb} / \mathrm{dL}$ whole blood (although a conditional one for cadmium has been introduced under the latest amendment to the Carcinogens and Mutagens Directive ${ }^{3}$ ). Even with a binding Biological Limit Value, the implementation varies widely, with many countries imposing their own, stricter, limits, e.g. $20 \mu \mathrm{g} / \mathrm{dL}$, Germany $^{4}$; and even the industry itself has set its own target of $20 \mu \mathrm{g} / \mathrm{dL}$ to be achieved by $2025^{5}$. Within the European countries, there is also much variation about how HBM programmes should be managed and by whom; some have very strict requirements for the full responsibility to be held by an occupational physician (e.g., Germany, Switzerland). Whilst the involvement of an occupational physician should always be encouraged, it is also true that physicians should seek to involve others, such as occupational hygienists, to help make the most of the data generated. Another surprising aspect of HBM in occupational health is the lack of current guidelines; those that do exist are often more than 20 years old $[4,9]$ and whilst much is still relevant, this perhaps does not encourage current wider use of HBM. In 2010, the ICOH scientific committee on occupational toxicology (SCOT) produced an overview of biomonitoring for occupational health risk assessment [10], which addressed issues such as definitions, interpretation of results and ethical considerations. I am also happy to report that several groups are currently assessing the available guidelines and looking to develop future strategies for encouraging and using HBM (OECD, ISES-EU6 ${ }^{6}$.

Examples of success may perhaps be the most convincing argument for promoting HBM as exposure assessment. The long-term monitoring of a carcinogenic polyurethane hardener, MbOCA, is a useful case study in highlighting the role of HBM in reducing exposure over time but also acknowledges the potential issues when setting "limits" or guidance values. MbOCA (methylenebis(orthochloro)aniline) is a solid at room temperature and is generally supplied in pellet form; it is melted before use; MbOCA is also readily absorbed through the skin. These facts make HBM the most appropriate monitoring approach; in Great Britain, urine monitoring for MbOCA has been recommended since at least 1987 when a biological monitoring guidance value (BMGV) was first established. This value was set at the 90th percentile (P90) of existing data ( $30 \mu \mathrm{mol} \mathrm{MbOCA} / \mathrm{mol}$ creatinine), therefore achievable, pragmatic and targeting the worst performers. Over time, as those "worst performers" improved, the $\mathrm{P} 90$ could be recalculated; a revised BMGV was set in 1996 (15 $\mu \mathrm{mol} \mathrm{MbOCA} / \mathrm{mol}$ creatinine [7]). Since then, further improvements in exposure have been observed (down to $3 \mu \mathrm{mol} \mathrm{MbOCA} / \mathrm{mol}$ creatinine) in

\footnotetext{
https://osha.europa.eu/en/legislation/directives/75

https://eur-lex.europa.eu/legal-content/EN/TXT/?uri = celex:32019L0983

https://onlinelibrary.wiley.com/doi/10.1002/3527600418.bb743992d0024

https:/ila-reach.org/2017/06/lead-and-lead-battery-industry-call-for-urgent-review-on-worker-exposure-limits/

https://ises-europe.org/group/exposure-data-production-human-data
} 
those companies demonstrating "good occupational hygiene practice" [11], but overall results have plateaued, indicating that the guidance value itself, when challenging, can drive improvement but that As Low As Reasonably Practicable $\left(\right.$ ALARP $^{7}$ ) or kaizen, a Japanese concept of continuous improvement [12], is not a universal force (despite the British BMGV documentation also stating, "Where biological monitoring results are below a particular guidance value, it does not mean that an employer need not take any further action to reduce exposure" [7]). Many with experience in occupational hygiene would agree that regulation and enforcement are some of the most powerful motivations for improvements in exposure control. It is therefore important that guidance values, especially those for carcinogens, mutagens and sensitisers where a principle of ALARP applies, are updated regularly to provide impetus for improvements but are also achievable. The case study for MbOCA illustrates a tenfold reduction in exposures over a 25 -year period, which is a substantial achievement. Although even at the current good practice levels of $\sim 3 \mu \mathrm{mol} \mathrm{MbOCA} / \mathrm{mol}$ creatinine, the cancer risk level of workers may still be several times higher than for unexposed workers [13].
By monitoring exposures, we can intervene where appropriate and take action to improve control measures and working practices. In situations where skin absorption can be significant or the control of exposure relies on personal protective equipment, HBM is often the most appropriate form of exposure assessment and should be used as such. Whilst there are considerations regarding ethics and communication, these should not be judged as unique to HBM but relevant to any well-managed exposure assessment programme. In the words of my colleague, "HBM is a useful tool, go and use it."

\section{Disclosure Statement}

Kate Jones is employed by the Health and Safety Executive, who provided support for this article. Its contents, including any opinions and/or conclusions expressed, are those of the author alone and do not necessarily reflect Health and Safety Executive policy in Great Britain.

7 https://www.hse.gov.uk/risk/theory/alarpglance.htm

\section{References}

1 Cocker J. A perspective on biological monitoring guidance values. Toxicol Lett. 2014 Dec;231(2): 122-5.

2 HSE. 2013. 'The Control of Substances Hazardous to Health Regulations 2002 (as amended). Approved Code of Practice and guidance', Accessed 19/05/2020. http://www.hse. gov.uk/pubns/priced/15.pdf

3 ACGIH. 2020. '2020 TLVs and BEIs', Accessed 19/05/2020. https://www.acgih.org/ forms/store/ProductFormPublic/2020-tlvsand-beis

4 HSE. 1997. 'Biological monitoring in the workplace: A guide to its practical application to chemical exposure', Accessed 23/05/19. http:// www.hse.gov.uk/pubns/books/hsg167.htm

5 Gee GC, Payne-Sturges DC. Environmental health disparities: a framework integrating psychosocial and environmental concepts. Environ Health Perspect. 2004 Dec;112(17): 1645-53.
6 Bolt HM, Meyer-Baron M, Reuter U, Schaller $\mathrm{KH}$, Seeber A, Triebig G. Mercury and its inorganic compounds, Addendum [BAT Value Documentation, 2010]. In: The MAK-Collection for Occupational Health and Safety: Annual Thresholds and Classifications for the Workplace. Hoboken: Wiley; 2010 [accessed 2020 May 18]. Available from https://onlinelibrary.wiley.com/doi/abs/ 10 . 1002/3527600418.bb743997anoe0005

7 HSE. 2020. 'EH40/2005 Workplace exposure limits', Accessed 19/05/2020. http://www.hse. gov.uk/pubns/priced/eh40.pdf

8 HSE. 2002. 'Control of lead at work (Third edition)', Accessed 19/05/2020. http://www. hse.gov.uk/pubns/books/1132.htm

9 WHO. Biological monitoring of chemical exposure in the workplace: guidelines. Geneva: WHO; 1996 [accessed 2020 May 18]. Available from https://apps.who.int/iris/handle/10665/41856
10 Manno M, Viau C, Cocker J, Colosio C, Lowry L, Mutti A, et al.; in collaboration with. Biomonitoring for occupational health risk assessment (BOHRA). Toxicol Lett. 2010 Jan; 192(1):3-16

11 Keen C, Coldwell M, McNally K, Baldwin P, McAlinden J, Cocker J. A follow up study of occupational exposure to $4,4^{\prime}$-methylenebis(2-chloroaniline) (MbOCA) and isocyanates in polyurethane manufacture in the UK. Toxicol Lett. 2012 Aug;213(1):3-8.

12 Cherrie JW. Kaizen. Ann Work Expo Health. 2017 May;61(4):398-400.

13 ECHA. Committee for Risk Assessment RAC Opinion on 4,4'-methylene-bis-[2-chloroaniline] (MOCA). Helsinki: ECHA; 2017 [accessed 2020 May 19]. Available from https:// echa.europa.eu/documents/10162/13641/ opinion_moca_en.pdf/35756093-0eb9-e4682ba2-786ca73c5aaa
Human Biomonitoring in Occupational Health for Exposure Assessment
Port J Public Health 2020;38:2-5 DOI: $10.1159 / 000509480$ 